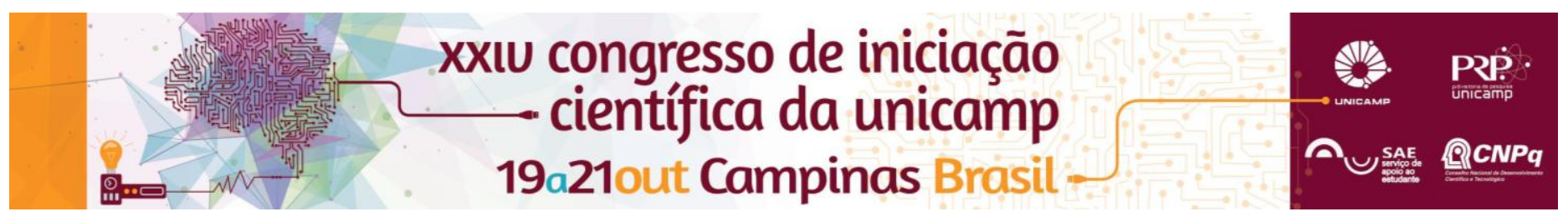

\title{
Fabricação e Estudo de Preformas de Fibra Óticas Microestruturadas
}

\author{
Alex J. Salvador*, Thiago H. R. Marques, Cristiano M. B. Cordeiro.
}

\section{Resumo}

O estudo de fibras ópticas poliméricas aplicadas a sensoriamento tem atraído muito interesse na última década. No caso de fibras microestruturadas uma das grandes vantagens é a vasta gama de estruturas que podem ser confecionadas. Nesse processo tudo começa com a fabricação de uma preforma que será posteriormente puxada para fibra. Aqui exploramos a técnica de furação de preformas através de um dispositivo CNC (Controle Numérico computadorizado) tendo obtido estruturas inovadoras que abrem um novo leque de sensores baseados em fibras ópticas microestruturadas poliméricas (mPOF).

\section{Palavras-chave:}

Fibra ótica, mPOF, fabricação de fibras, CNC, fibra óptica microestruturas

\section{Introdução}

Fibras ópticas poliméricas, mesmo apresentando alta perda óptica quando comparadas com fibras de sílica, podem ser bastante interessantes e fabricadas com uma grande gama de geometrias. Dentre as diferentes técnicas de produção de preformas (empilhamento, casting, etc), a furação via CNC é uma das mais eficientes e práticas. Além de proporcionar alta qualidade à preforma é um processo automatizado incrivelmente preciso. Neste trabalho mostraremos algumas estruturas exóticas produzidas em nosso laboratório e que dificilmente podem ser obtidas em fibras de vidro.

\section{Resultados e Discussão}

O ponto importante quando se discute a geometria de um guia de onda, fibras ópticas neste trabalho, é o fato das propriedades destas estarem intimamente ligadas ao padrão de buracos da estrutura.

Uma vez decidida a principal funcionalidade da fibra óptica a ser fabricada, é feito o desenho da preforma usando o programa de modelagem 3D como mostra a figura 1. Logo em seguida, esse desenho é exportado em código $\mathrm{G}$ e essa será a entrada usada no programa Mach3 ${ }^{\circledR}$ que controla o CNC.
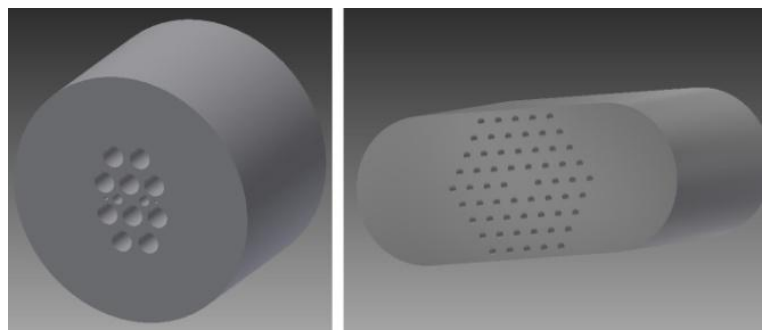

Figura 1. Exemplos de desenhos feitos com o no programa de modelagem 3D.

O próximo passo no processo é a furação (furos tipicamente com 1,5 a 5,0 mm) do tarugo de acrílico (PMMA). Esse material foi escolhido por ter uma janela de baixa perda no espectro visível e poder ser puxado para fibra óptica em temperaturas da ordem de 200 graus. Este é também um material facilmente encontrado no formato de tarugos sólidos de elevada transparência. Uma limitação básica do processo é o pequeno comprimento que pode ser furado. Esta limitação se deve ao comprimento das brocas utilizadas. Fazendo a furação pelos dois lados do tarugo chega-se, tipicamente, a preformas com $90 \mathrm{~mm}$ de altura.

$\mathrm{Na}$ figura 2, vemos o nosso CNC bem como algumas preformas com geometrias incomuns.
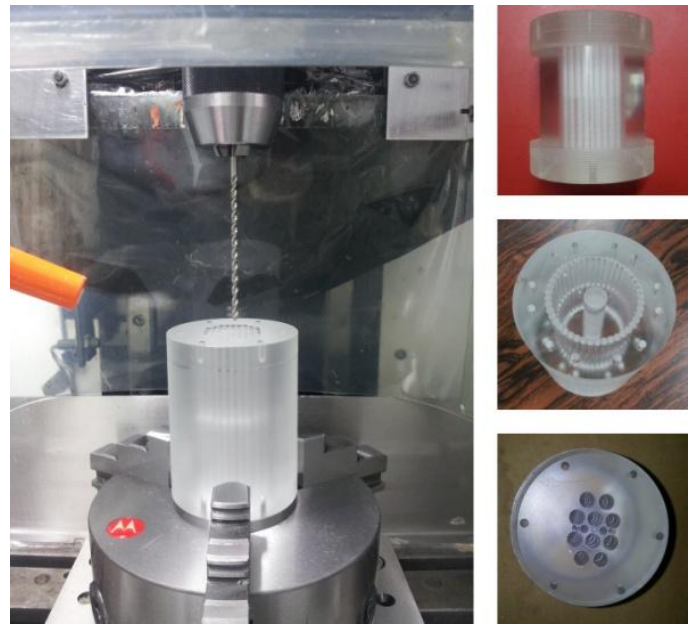

Figura 2. Furadeira CNC usada para as furações e tarugos furados e com geometrias bem diferentes.

O último passo no estágio de fabricação é o puxamento da fibra em si, o que também é feito em nosso laboratório [1]. Na fibra toda a geometria é reduzida tendo o mesmo diâmetro externo típico de 0,2 a 1,0 mm.

\section{Conclusões}

Temos, pois, uma infraestrutura de produção de fibras ópticas microestruturadas poliméricas única no Brasil uma vez que, além do CNC, contamos com uma torre dedicada ao puxamento das mPOFs [1].

\section{Agradecimentos}

Os autores agradecem ao CNPq (bolsa \#477209/2013-0) pelo apoio financeiro e Tayná Nakamura pela etapa inicial deste trabalho.

1 Marques, T. H. R.; Salvador, A. J; Cordeiro, C. M.; Fabrication of Microestrutured Polymer Optical Fibers; XXIV Congresso de Iniciação Científica da Unicamp, 2016. 